\title{
The Effectiveness of Brain Gym and Brain Training Intervention on Working Memory Performance of Student with Learning Disability
}

\author{
Bungawali Abduh, Mohd Mokhtar Tahar \\ Universiti Kebangsaan Malaysia, Malaysia \\ Email: bungaduan@gmail.com
}

\begin{abstract}
Learning disability is commonly associated with a weak working memory function of a student that impacts his or her performance in school. This study aims to identify the effective approaches that could enhance the working memory function of students with learning disability. This quasi-experimental study involved three group of five students that were allocated into control group, Brain Gym, and Brain Training intervention group. The Brain Gym intervention group performed Brain Gym ${ }^{\circledR}$ Superspace exercise on a daily basis for four weeks during the first school session. Meanwhile, Brain Training intervention was carried out by another intervention groups on a daily basis for four weeks. They were allocated with 5-minutes Brain Training game for each person in a group during free time at school. Data for the working memory function that were collected during pre- and post-test using three instruments: (1) Digit Span Memory Test; (2) Spatial Memory Test; and (3) Picture Identification Test. Two nonparametric test was used to interpret the data: (1) Spearman Rank Order Correlation to determine the relationship of the three groups on the pre- and post-test and Wilcoxon Pair Signed Rank Test to measure the difference between pre- and post-test scores for the control group, two intervention groups, and three working memory component. The findings of the study show a significant increment of the working memory function for both intervention groups. The finding also shows a significant increment for Digit Span Memory and Spatial Memory skills among participants in the intervention group. This study provides alternative to parents, teachers and school administration to provide appropriate learning stimulus that could fulfill the needs of students in school and at home.
\end{abstract}

Keywords: working memory, students with learning disability, brain gym, brain training

\section{INTRODUCTION}

What causes learning disabilities?. According to researches there are various factors that cause difficulties in learning including imperfect formation of ears and hearing senses that affect early learning as early as in the womb (Wasserman et al., 2012), imbalance brain chemical caused by the imperfection of neurotransmitter function (Healy, 2004), birth trauma and emotional trauma during developmental process which causes disability learning failure associated with sensory integration and executive functions of the brain (May-Benson et al., 2009), allergies and nutritional aspects that influence the performance of children at school (Phyllis, 2013).

The significant relationship between sensory integration development and executive functions of the brain draws researchers' attention when the developmental impairment of the brain function was proven to be able to be treated in the previous study with improving relations between neuron cells. The process that is known as neuroplasticity happens when the needs of the metabolic neuron could be increased with the increment of the intensity of the brain stimulus (Leisman \& Melillo, 2015). Therefore, this study was carried out to measure the appropriate and effective method that can be implemented by the teacher in the classroom to enhance the brain stimulation of students with learning disability.

Many recent studies were conducted to measure the steps in boosting the stimulation to the capacity of the most basic brain function that is working memory. For example, body movement (Vicary et al., 2014; Sousa, 2017) and games using software and devices that involve imagination and combination of ideas (Durkin et al., 2013; Cardoso-Leite \& Bavelier, 2014; Titz \& Karbach, 2014). However, these studies have limited the focus on a single method of brain stimulation without looking at the different perspective of other methods that could be appropriate for readers' comparison and consideration, especially parents and those involved in teaching. Hence, the researcher has put an emphasis on the working memory performance through the implementation of two types of cognitive intervention, Brain Gym ${ }^{\circledR}$, and Brain Training. The outcome of the study will look at the effectiveness of the intervention towards working memory performance of the students involved as well as to determine the scores' difference of working memory performance between different groups of students that received a different intervention. 
Figure 1. Baddeley Working Memory Model (2012)

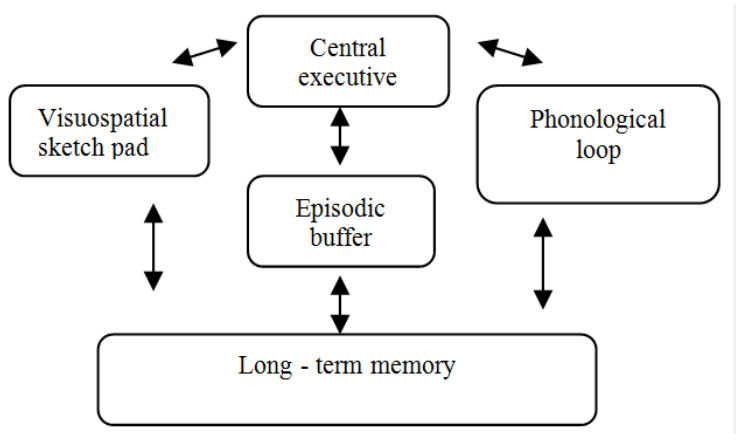

Working memory is an early process of brain function that is crucial for the learning process. It provides temporary storage of information necessary for a more complex learning activity (Baddeley, 2012). In 1974, Baddeley \& Hitch proposed a model of working memory that becomes an alternative to various models of memory storage.

The above diagram is the main component of Baddeley's working memory model that is led by executive functions, the most important component which plays a role in synthesizing received information. Episodic Buffer responsible for recalling information, integrating and manipulating materials depending on the executive process. The Visual-Spatial Scratch Pad stores nonverbal visual and spatial information like objects and numbers. The study found that the limits of visual-spatial memory capacity (between 4 to 7 items) are depending on the level of focus and the methods used (Cowan, 2001; Zimmer et al., 2010). On the other hand, the Phonological loop is a part of that stores a limited number of speech sounds for a short period. Some previous studies found that there is a significant relationship between working memory and IQ level as working memory practices were found to improve individuals IQ (Norbert \& Ksenija, 2012; Smith, 2015). In addition, the working memory also has a strong relationship with the intellectual capacity when it is used as intervention on a wide range of specific populations like children with ADHD (Chacko et al., 2014), Down syndrome (Costa et al., 2015), dyslexic students (De Carvalho et al., 2014) and individuals with autism (Kercood et al., 2014).

According to the founder of Brain $G y m \AA$, Dennison, the foundation of Brain Gym is the interdependence of movements, cognitive and learning process. Some previous studies found that Brain Gym practices give a positive impact on students' academic performance, motivation, balancing and focus level (Sutoro, 2014; Rehab, 2017 \& Gibbs, 2007). On the other hand, Brain Training refers to the participation in certain activities or programs that aims to improve cognitive ability resulted from the repetition of activities over a period of time. It involves the control function that requires focus, intelligent and the control of misleading stimulus including reasoning, working memory and inhibitory control (Owen et al., 2010; Howard-Jone, 2014; Ballesteros et al., 2015).

Brain Gym ${ }^{\circledR}$ and Brain Training interventions are two different approaches that focus on students' engagement in activity to impact the neuroplasticity process and brain executive function particularly working memory performance and productivity of life. Both commercial approach interventions always draw researchers' attention who questioned its effectiveness. The issues on Brain Gym revolved around the underlying theories that are said to be empirical when previous studies failed to show scientific evidence and a dispute in the outcome of findings analysis (Hyatt, 2007; Spaulding et al., 2010; Ruhaak \& Cook, 2016). Next, Brain Training intervention which is based on cognitive training through games like Cogmed, Lumosity and Cognifit is questioned by previous researchers when their impact on neural functioning was not relevant to the achievement of lesson in class and real-life practices as alleged by the brain training company (Simons et al., 2016 \& McCabe et al., 2016). The relationship between Brain Training and academic achievement has also raised an issue as it does not involve the body movement that is already proven to improve executive function of the brain (Horward-Jones, 2014). The disagreement and issues on the effectiveness of Brain Gym and Brain Training draw researcher's interest to conduct this study. This study aims to measure the effectiveness of Brain Gym and Brain Training Intervention towards the working memory performance of students with learning disability in a primary school in Bangi. Therefore, the objectives of this study are: (i) To compare the working memory performance of two intervention groups and control group before and after the intervention program; (ii) To find out which component of working memory have improved after the intervention program.

\section{METHOD}

This study employed a quasi-experimental design that involved 15 students with learning disability using purposive sampling method. The participants involved are only those who are classified to have learning disabilities based on Registration Form and Special Needs Placement of Children (0-18 years). A pre-test was carried out to all participants before they were segregated into 3 groups based on the matched-group design (Elizabeth \& Rubin, 2007; Creswell, 2013). The participants were sorted out in ranking based on the pretest scores earned. They pulled out alternately to join the three different group based on the score ranking. Consequently, each group will have five members (control group; Brain Training Intervention group; 
Brain Gym ${ }^{\circledR}$ Intervention group) that is equivalent in terms of cognitive abilities based on the mean score of each team. The population involved in the study is the accessible population (Noraini, 2013) which consist of all 44 students from the integration program of a secondary school in Bangi. The size of the sample is equivalent to $34 \%$ of the study population and each sample represents 3 students in the population. This value is calculated based on the Mathematics formula adopted from Barreiro \& Albandoz (2001).

The consents from the school and parents were obtained before the study was conducted. The pilot study was conducted using the test-retest method to determine the reliability of the instrument. The participants involved in the intervention process were also given a briefing about the form of intervention, the aims and the duration of the study. This procedure is taken to ensure that every participant would be able to give full cooperation and commitment throughout the interventions that were held for 4 weeks. During the implementation of this study, the researcher had accomplished a course on Brain Gym ${ }^{\circledR} 107$ and obtained a certificate of completion of the course. The pre-test and post-test were conducted in a controlled and natural setting of the classroom. The scores obtained for pre-test (before intervention) and posttest (after 4 weeks of intervention) were recorded in the same data form for each participant so that a clear score comparison can be made for each participant. The Brain Gym ${ }^{\circledR}$ intervention with six Superspace movement ( Brain Button, Space Button, Earth Button, Thinking Cape, Cross Crawl and Hook-ups) was carried out by one intervention group for 5 minutes during early school time on a daily basis. It started with drinking of plain water before conducting any physical movement. On the other hand, Brain Training intervention was carried out by the other intervention groups during free time for five minutes on a daily basis. Brain Training included 5 games that were downloaded using a mobile phone and a tablet from Google Play Store. The Brain Training games were Left VS. Right, Lumosity, Cogmed, Memory Game and Memory Test. While the control group of this study did not receive any intervention stimulus.

The best measurement of working memory performance involves a combination of different tests to produce a score with high reliability and validity (Kane et al., 2005). As a result, three types of instruments in the form of cognitive computerized tasks on mobile devices were used to measure the working memory performance during pre- and post-test to allow assessments to be performed in the variety of environments (Satler et al., 2015). Digit Span Memory Test and Spatial Memory Test are two common tests that were used in cognitive and neuroscience studies.
In this study, both tests had been freely accessed from the website www.memorylosstest.com. Digit Span Memory Test is similar to the Wechsler Intelligence Test Score for Children (WISC-R) (Wechsler, 1974). The difference between the two tests is the auditory stimulus used for WISC-R while the visual stimulus is used for Digit Span Memory Test which 5 random numbers will appear sequentially in the tablet screen before they disappear. The participants have to touch the numbers on the screen so that the same digits reappeared with the right sequence.

On the other hand, Spatial Memory Test was adopted from Korsi Blok (Milner, 1971) that involved a sequenced movement of the items in the certain location on the screen. Participants were asked to memorize the sequence of the items appeared in certain locations. Each participant is given 10 attempts for both tests. The third instrument is Picture Identification Test that is developed and adopted from the Recognition Memory for Related Pictures by Pezdek (1978). In this test, the participants were shown 30 images that appear in a row every 3 times. After that, participants were asked to choose one of two pictures that appeared simultaneously by saying A or B for each of the 30 pairs of pictures presented. The researcher refers two experts to review and confirm each modified instrument.

Data analysis was carried out using IBM SPSS Statistics 22 with $\mathrm{P}<0.05$ as the significant value. The data of the pilot study was tested using Spearman Rank-order correlation to determine the relationship of scores obtained before and after the intervention. The Spearman Rank-order correlation analysis on the scores of working memory performance before and after intervention illustrates a strong and positive relationship with the significant value $(\mathrm{r}=0.817, \mathrm{P}$ $=0.000$ ). The analysis of Wilcoxon Matched-Pairs Signed Rank Test was used to see the scores' difference of working memory performance before and after the intervention programs for all three group. A nonparametric test was selected for the analysis as the study involved only a small sample size for every study group.

\section{FINDINGS AND DISCUSSION}

\section{Findings}

\section{Group Scores of Working Memory Performance before after Intervention}

The comparison of post-test and pre-test performance scores was done separately to see if there is a significant difference between working memory performance for the control group and both intervention groups. 
Table 1. Wilcoxon Signed Rank Test Analysis of Working Memory Performance Before and After Intervention for three group.

\begin{tabular}{|c|c|c|c|c|c|c|}
\hline & & & $\mathrm{N}$ & $\begin{array}{l}\text { Mean } \\
\text { Rank }\end{array}$ & $\mathrm{z}$ & Sig \\
\hline \multirow[t]{4}{*}{ Control } & Pre & $\begin{array}{l}\text { - tive } \\
\text { Rank }\end{array}$ & $2^{a}$ & 3.00 & -.405 & .686 \\
\hline & Post & $\begin{array}{l}\text { +tive } \\
\text { Rank }\end{array}$ & $3^{b}$ & 3.00 & & \\
\hline & & Ties & 0 & & & \\
\hline & & Total & 5 & & & \\
\hline \multirow[t]{4}{*}{ BT } & Pre & $\begin{array}{l}\text { - tive } \\
\text { Rank }\end{array}$ & $0^{\mathrm{a}}$ & .00 & -2.023 & .043 \\
\hline & Post & $\begin{array}{l}+ \text { tive } \\
\text { Rank }\end{array}$ & $5^{b}$ & 3.00 & & \\
\hline & & Ties & $0^{c}$ & & & \\
\hline & & Total & 5 & & & \\
\hline \multirow[t]{4}{*}{ BG } & Pre & $\begin{array}{l}\text { - tive } \\
\text { Rank }\end{array}$ & $0^{\mathrm{a}}$ & .00 & -2.041 & .041 \\
\hline & Post & $\begin{array}{l}+ \text { tive } \\
\text { Rank }\end{array}$ & $5^{b}$ & 3.00 & & \\
\hline & & Ties & $0^{c}$ & & & \\
\hline & & Total & 5 & & & \\
\hline
\end{tabular}

*BT (Brain Training), BG (Brain Gym)

Based on output analysis in table 1 , there is no significant difference in control group working memory performance before and after intervention program $(\mathrm{z}=$ $-.405, \mathrm{P}=.686$ ).

\section{Brain Training Intervention}

Based on Table 1, there is a significant difference in the working memory performance before and after the Brain Training intervention program $(\mathrm{z}=-2.023$, $\mathrm{P}=.043)$. All participants show improvement in their working memory scores after the completion of Brain Training intervention. These findings demonstrate Brain Training has successfully increased the working memory performance scores of the participants. The outcome of the analysis has proven that Brain Training intervention could improve students' working memory performance.

The findings of this research are associated with several factors that drive an efficient selection of focus to enhance working memory performance. An active adaptation on the establishment of attention and focus is required for the implementation of Brain Training Intervention in a natural setting. However, the extrinsic motivation gained from the friends and teachers and intrinsic motivations that were portrayed in attention and interest encourage participants involved to achieve the targeted level in Brain Training games. Lumosity and Cogmed are two interesting games in Brain Training that could attract participants and increase their motivation to try out other interactive games that have been set and scheduled.
The games were not only testing participants' skills in focusing, but also enhancing their skills and ability to memorize, be flexible, solve the problem, listen and language. The stimulation gained by the participants from the Brain Training and other learning game increased positive emotion that influenced participants' engagement in learning throughout school session (Dewi \& Kurniawan, 2017). The findings of this study are supported by Mawjee et al. (2014), Nouchi et al. (2013), and Holmes \& Gathercole (2014) which concluded that working memory training sessions could drive engagement, motivation, working memory, math skills and increased of participant expectation.

\section{Brain Gym ${ }^{\circledR}$ Intervention}

Based on Table 1, there is a significant difference on the working memory performance before and after intervention program $(\mathrm{z}=-2.041, P=.041)$. All participants show improvement in their working memory scores after the completion of Brain Gym intervention. This findings demonstrate Brain Gym ${ }^{\circledR}$ Superpace exercise that was conducted for 4 weeks has successfully increased the working memory performance scores of the participants. This outcome contradicted with the findings of Watson \& Kelso (2014) that suggest a longer period for Brain Gym to be more effective. Unlike the research conducted by Watson \& Kelso (2014), Brain Gym ${ }^{\circledR}$ Intervention that was conducted for four weeks during early school session took about 5 minutes for completion.

The researcher has made some considerations on the maturity-bias influence (Mitchell \& Jolley, 2012), motivation (Toril et al., 2014) and cost (Simon, 2016) to determine a suitable duration for Brain Gym ${ }^{\circledR}$ Intervention. This was supported by Metcalf et al. (2012), who suggests the intervention of physical activity to be conducted for 4 weeks of duration.

The finding of this study is similar to some previous studies showing positive results for the intervention group after implementing the Brain Gym. For instance, the findings of a study by Marpaung et al. (2017) on academic performance and Rehab (2017) on balancing and manipulative skills. Current and previous studies provide a different perspective on Brain Gym that makes it relevant for consideration of Brain Gym ${ }^{\circledR}$ in the school setting. Among the Brain Gym activities include 26 types of gradual Brain Gym movement which encompasses three dimensions of fitness that are the focus, centering and laterality (Koester, 2013). The implementation of a program that is interesting, easy and fulfills the needs of every student in a less-restrictive environment is very important in enhancing motor perception process of students with the learning disability (Stephenson et al., 2007). This effort includes all physical activity, exercise movement, dance and Brain Gym ${ }^{\circledR}$ movement. 
Table 2. Wilcoxon Signed Rank Test Analysis of working memory components.

\begin{tabular}{llcccc}
\hline & & N & $\begin{array}{c}\text { Mean } \\
\text { rank }\end{array}$ & z & Sig \\
\hline Post- & -tive & $0^{\text {a }}$ & .00 & -2.264 & .024 \\
DSMT & Rank & & & & \\
Pre- & +tive & $6^{\text {b }}$ & 3.50 & & \\
DSMT & Rank & & & & \\
& Ties & $4^{c}$ & & & \\
& Total & 10 & & & \\
& & & & & \\
Post- & -tive & $0^{\text {a }}$ & .00 & -2.214 & .027 \\
SMT & Rank & & & & \\
Pre- & tive & $6^{\text {b }}$ & 3.50 & & \\
SMTl & Rank & & & & \\
& Ties & $4^{c}$ & & & \\
& Total & 10 & & & \\
& & & & & \\
Post-PIT & -tive & $1^{\text {a }}$ & 3.50 & -1.480 & .139 \\
& Rank & & & & \\
Pre-PIT & tive & $5^{\text {b }}$ & 3.50 & & \\
& Rank & & & & \\
& Ties & $4^{4}$ & & & \\
& Total & 10 & & & \\
\hline
\end{tabular}

*DSMT(Digit Span Memory Test), SMT (Spatial

Memory Test), PIT( Picture Identification Test)

Performance of working memory component after intervention program

Table 2 shows the performance comparisons of each working memory components before and after the intervention program for both intervention groups.

The significant changes were recorded on DSMT $(\mathrm{Z}=-2.2643, \mathrm{P}=0.024)$ and $\operatorname{SMT}(\mathrm{Z}=-2.214, \mathrm{P}=$ $.027)$ skills of the participants. Six participants show a higher score of DSMT and SMT after intervention and 4 participants did not show any score changes. It shows that intervention provides positive changes to the working memory performance of DSMT and SMT skills. There were no significant changes observed in the PIT test $(Z=-1.480, P=0.139)$ when intervention was implemented.

The outcome of the analysis has proven that intervention programs could improve students' working memory performance in the aspect of memorizing the spatial map location, numbers, and its position. In the Digit Span Memory Test that was implemented in this study, participants are required to memorize 5 digits that appear one by one in less than 5 seconds in duration. After that, participants are required to use their working memory capacity to type and obtain the 5 digits number on display screen. The intervention that took place in the study provides a positive implication towards the capacity limit of visual-spatial memory for students with learning disability. The participants involved in the intervention able to achieve the capacity limit of visual-spatial memory within the range between 4 and 7 items as stated in previous studies (Zimmer et al., 2010; Cowan, 2001).

The improvement of visual-spatial skills in this study is similar to the findings of Astle et al. (2015). In the study, 33 children involved in a spatial memory training. As a result, their working memory capacity associated with altered connectivity between the frontoparietal network and both parietal cortex and inferior temporal cortex is increased. In consequence, their focus level is also improving based on the fact that working memory is associated with the ability to concentrate selectively (Kreitz et al., 2015). This study proves that the stimulation of brain training and consistent physical movement will improve the nature of plasticity and brain function. It allows the brain to adapt to environmental changes as well as enable the encoding of memories of episodes and places (Constantinidis \& Klingberg, 2016).

\section{CONCLUSION}

This study is a form of exploration on brain training interventions involving physical activity and computerized training to measure the working memory performance of students with learning disability. Brain Training and Brain Gym ${ }^{\circledR}$ intervention was successful in enhancing participants working memory performance. The two components of working memory also improved and it is proven when students's ability to recall 5 numbers in correct order and visual spatial skill increased significantly.

For future studies, a random selection of participants within a larger population can be made so that the findings can be generalized while providing equal opportunity to all members of the population to get involved in the study. The findings of past and current studies can be used as a guide for the teachers and researchers in applying the brain training and physical activity while teaching in the classroom. These efforts could enhance sensorial integration and brain executive function for a more meaningful and interesting learning experience.

\section{REFERENCES}

Astle D. E., Barnes J. J., Baker K., Colclough G. L., \& Woolrich M. W. 2015. Cognitive Training enhances intrinsic brain connectivity in childhood. The Journal of Neuroscience, 35(16), 6277-6283.

Baddeley, A. (2012). Working memory: theories, models, and controversies. Annual review of psychology, 63, 1-29. 
Ballesteros, S., Mayas, J., Prieto, A., Toril, P., Pita, C., Laura, P. D. L., \& Waterworth, J. A. (2015). A randomized controlled trial of brain training with non-action video-games in older adults. Result of the 3-month follow-up. Frontiers in aging neuroscience: Clinical Trial, 7,(45), 1-12.

Barreiro, P. L., \& Albandoz, J. P. (2001). Population and sample. Sampling techniques. University of Seville: Management Mathematics for European Schools.

Cardoso-Leite, P., \& Bavelier, D. (2014). Video game play, attention, and learning: how to shape the development of attention and influence learning. Current opinion in neurology, 27(2), 185-191.

Chacko, A., Kofler, M., \& Jarrett, M. (2014). Improving outcomes for youth with ADHD: A conceptual framework for combined neurocognitive and skill-based treatment approaches. Clinical Child and Family Psychology Review, 17(4), 368-384.

Constantinidis, C., \& Klingberg, T. (2016). The neuroscience of working memory capacity and training. Nature Reviews Neuroscience, 17(7), 438.

Costa, H. M., Purser, H. R. M., \& Passolunghi, M. C. (2015). Improving working memory abilities in individuals with Down syndrome: a treatment case study. Frontiers in psychology, 6, 1331.

Cowan, N. (2001). The magical number 4 in shortterm memory: A reconsideration of mental storage capacity. Behavioral and Brain Sciences, 24, 87185.

Creswell, J. W. (2013). Research Design: Qualitative, quantitative and mixed methods approaches. Singapore: Sage.

Dewi, N. S., \& Kurniawan, A. (2017). The Effect of Scramble Game Towards the Ability of Composing Sentences for Students with Intellectual Disability. Journal of ICSAR, 1(1), 81-84.

De Carvalho, C. A., Kida, A. D. S., Capellini, S. A., \& de Avila, C. R. (2014). Phonological working memory and reading in students with dyslexia. Frontiers in psychology, 5, 746.

Durkin, K., Boyle, J., Hunter, S., \& Conti-Ramsden, G. (2015). Video games for children and adolescents with special educational needs. Zeitschrift für Psychologie, 221(2), 79-89.

Elizabeth, A. S., \& Rubin, D. B. (2007). Best Practises in quasi-experimental designs: Matching Methods for causal inference. Best Practise in research design.

Gibbs, K. L. (2007). Study regarding the effect of Brain Gym on Student Learning. Education and Human Development Master's Theses.
Healy, J. M. (2004). Your Child's growing mind: Brain development and learning from birth to adolescence. New York: Broadway Books.

Holmes, J., \& Gathercole, S. E. (2014). Taking working memory training from the laboratory into schools. Educational Psychology, 34(4), 440-450.

Horward-Jones, P. (2014). Neuroscience and Educational: A review of educational intervention and Approaches informed by Neuroscience; Full report and executive summary. Education Endowment Foundation (BEF). Bristol : University of Bristol.

Hyatt, K. J. (2007). Building stronger brains or wishful thinking. Remedial and Special Education, 28(2), 117-124.

Kane, M. J., Hambrick, D. Z., \& Conway, A. R. (2005). Working memory capacity and fluid intelligence are strongly related constructs: Comment on Ackerman, Beier and Boyle. Psychological Bulletin, 131(1), 66-71.

Kercood, S., Grskovic, J. A., Banda, D., \& Begeske, J. (2014). Working memory and autism: A review of literature. Research in Autism Spectrum Disorders, 8(10), 1316-1332.

Koester, C. (2013). Course Manual for Brain Gym 101s: Interfacing Brain Gym with children who have special needs. Ventura Canada: The Educational Kinesiology Foundation.

Kreitz, C., Furley, P., Memmert, D., \& Simons, D. J. (2016). The influence of attention set, working memory capacity, and expectations on inattentional blindness. Perception, 45(4), 386-399.

Leisman, G., \& Melillo, R. (2015). The plasticity of brain networks as a basis for a science of nervous system rehabilitation. Int $J$ Neurorehabil, 2(2), 155.

Marpaung, M. G., Sareharto, T. P., Purwanti, A., \& Hermawati, D. (2017). Brain Gym To Increase Academic Performance Of Children Aged 1012 Years Old (Experimental Study in Tembalang Elementary School and Pedalangan Elementary School Semarang). In IOP Conference Series: Earth and Environmental Science, 55(1), 12-17.

Mawjee, K., Woltering S., Lai N., Gotlieb H., Kronitz R., \& Rosemary, T. (2014). Working Memory Training in ADHD: Improvement pilot study. Journal of Attention Disorder: 1-13.

May-Benson, T. A., Koomar, J., \& Teasdale, A. (2009). Incidence of pre-, peri-, and post-natal birth and developmental problems of children with sensory processing disorder and children with autism spectrum disorder. Frontiers in integrative neuroscience, 3, 31 . 
McCabe, J. A., Redick, T. S., \& Engle, R. W. (2016). Brain-training pessimism, but applied-memory optimism. Psychological Science in the Public Interest, 17(3), 187-191.

Metcalf, B., Henley, W., \& Wilkin, T. (2012). Effectiveness of intervention on physical activity of children: systematic review and meta-analysis of controlled trials with objectively measured outcomes (EarlyBird 54). BMJ, 345.

Milner, B. (1971). Interhemispheric Differences in the Localization of Psychological Processes in Man. British Medical Bulletin, 27, 272-277

Mitchell, M. L. \& Jolley, J. M. (2012). Research design explained (8th edition). Australia; Belmont, CA: Wadsworth Cengage Learning.

Noraini, I. (2013). Penyelidikan dalam pendidikan. Shah Alam: Mc Graw Hill.

Norbert, J. \& Ksenija J. (2012). Working memory training: improving intelligence-changing brain activity. Brain and Cognition, 79(2), 96-106.

Nouchi, R., Taki, Y., Takeuchi, H., Hashizume, H., Nozawa, T., Kambara, T., \& Kawashima, R. (2013). Brain training game boosts executive functions, working memory and processing speed in the young adults: a randomized controlled trial. PloS one, 8(2).

Owen, A. M., Hampshire, A., Grahn, J. A., Stenton, R., Dajani, S., Burns, A. S., \& Ballard, C. G. (2010). Putting brain training to the test. Nature, 465(7299), 775.

Pezdek, K. (1978). Recognition memory for related pictures. Memory \& Cognition, 6(1), 64-69.

Phyllis, B. (2013). Reversing Dyslexia: Improving learning \& behavior Without drugs. USA: Square One Publisher.

Rahab, H. (2017). Effect of Brain Gym on Manipulating Skills And Balance For Beginners In Rhythmic Gymnastics. Ovidius University Annals, Series Physical Education \& Sport/Science, Movement \& Health, 17(1).

Ruhaak, A. E., \& Cook, B. G. (2016). Movement as behavioral moderator: what does the research say?. In Instructional Practices with and without Empirical Validity (pp. 111-134). Emerald Group Publishing Limited.

Satler, C., Belham, F. S., Garcia, A., Tomaz, C., \& Tavares, M. C. H. (2015). Computerized spatial delayed recognition span task: a specific tool to assess visuospatial working memory. Frontiers in aging neuroscience, 7(53), 1-9.
Simons, D. J., Boot, W. R., Charness, N., Gathercole, S. E., Chabris, C. F., Hambrick, D. Z., \& StineMorrow, E. A. (2016). Do "brain-training" programs work?. Psychological Science in the Public Interest, 17(3), 103-186.

Smith, M. A (2015). Review of 2014-2015 Metaanalyses on Working Memory Training for IQ and working memory.

Sousa, D. A. (2017). How the brain learns (fifth edition). US: Corwin Press

Spaulding, L. S., Mostert, M. P., \& Beam, A. P. (2010). Is Brain Gym ${ }^{\circledR}$ an effective educational intervention?. Exceptionality, 18(1), 18-30.

Stephenson, J., Carter, M., \& Wheldall, K. (2007). Still jumping on the balance beam: Continued use of perceptual motor programs in Australian schools. Australian Journal of Education, 51(1), 6-18.

Sutoro, S. (2014). Influence of BrainGym on Mathematical Achievement of Children. Asian Social Science, 10(5), 114.

Titz, C., \& Karbach, J. (2014). Working memory and executive functions: effects of training on academic achievement. Psychological research, 78(6), 852-868.

Toril, P., Reales, J. M., \& Ballesteros, S. (2014). Video game training enhances cognition of older adults: a meta-analytic study. Psychology and aging, 29(3), 706.

Vicary, S. A., Robbins, R. A., Calvo-Merino, B., \& Stevens, C. J. (2014). Recognition of dance-like actions: Memory for static posture or dynamic movement?. Memory \& Cognition, 42(5), 755767.

Wasserman, E. E., Pillion, J. P., Duggan, A., Nelson, K., Rohde, C., Seaberg, E. C., ... \& Rose, N. R. (2012). Childhood IQ, hearing loss, and maternal thyroid autoimmunity in the Baltimore Collaborative Perinatal Project. Pediatric research, 72(5), 525.

Watson, A., \& Kelso, G. L. (2014). The Effect of Brain Gym ${ }^{\circledR}$ on Academic Engagement for Children with Developmental Disabilities. International Journal of Special Education, 29(2), 75-83.

Wechsler, D. (1974). Wechsler Intelligence Scale for Children-Revised. New York: Psychological Corporation.

Zimmer, H. D., Münzer, S., \& Umla-Runge, K. (2010). Visuo-spatialWorking Memory as a Limited Resource of Cognitive Processing. In Resourceadaptive cognitive processes (pp. 13-34). Springer, Berlin, Heidelberg. 